\title{
The Roles of Interlocutor in Second Language Acquisition
}

\author{
Songlin Yang ${ }^{1}$, Yao Zhao ${ }^{1, *}$ \\ ${ }^{1}$ Foreign Languages College, Beihua University, Jilin, Jilin Province, China \\ ${ }^{*}$ Corresponding author
}

\begin{abstract}
Key words: second language acquisition, interlocutor, roles
\end{abstract}
\begin{abstract}
As for the variants cropping up in the output of second language learners, we have the responsibility to explain them, and in return, they will serve as a guide in our teaching practice. This paper attempts to analyze it from the interlocutor's social status, familiarity with the speaker, proficiency of the target language and appropriateness of feedback.
\end{abstract}

\section{Introduction}

Elaine Tarone discusses the second language acquisition from the perspective of analyzing the interlanguage variations in her "Situational Context, Variation, and Second Language Acquisition Theory".

The idea of interlanguage is founded upon the assumption that an L2 learner, at any particular moment in his learning sequence, is using a language system which is neither the L1, nor the L2. It is a third language, with its own grammar, its own lexicon and so on.

Valid though the interlanguage perspective may be, which views learner language as a language in its own right, this language varies much more than native-speaker language, in an apparently chaotic way. A learner may exhibit very smooth, grammatical language in one context and uninterpretable gibberish in another.

Scholars from different traditions have taken opposing views on the importance of this phenomenon. Those who bring a Chomskyan perspective to second language acquisition typically regard variability as nothing more than "performance errors", and not worthy of systematic inquiry. On the other hand, those who approach it from a sociolinguistic or psycholinguistic orientation view variability as a key indicator of how the situation affects learners' language use. Naturally, most research on variability has been done by those who presume it to be meaningful, because variation "is a source of information about the way in which interaction in different social contexts can influence both interlanguage use and overall interlanguage development" [1].

Research on variability in learner language distinguishes between "free variation", which takes place even within the same situation, and "systematic variation", which correlates with situational changes.

Free variation, the variation without any determinable pattern, is itself highly variable from one learner to another. To some extent, it may indicate different learning styles and communicative strategies. Learners that favor high-risk communicative strategies and have an other-directed cognitive style are more likely to show substantial free variation, as they experiment freely with different forms.

And systematic variation consists of linguistic motivated and sociologically motivated aspects.

Linguistic factors are usually extremely local. For instance, the pronunciation of a difficult phoneme may depend on whether it is to be found at the beginning or end of a syllable. 
Sociologically motivated aspect may include factors such as social factors, task, topic etc., among which, interlocutor holds the overriding significance.

As for the concept of interlocutor, while, in a one-to-one scenario, it refers to someone who takes part in a conversation, whose counterpart's performance is usually the focus of our observation and research. Depending on the context, the interlocutor is more than a passive listener. The interlocutor has the role of reacting, positively or negatively, to the speaker's speech.

This paper is to elaborate its roles from the four perspectives, namely, interlocutor's social status, his/her familiarity with the speaker, proficiency of the target language, and appropriateness of feedback.

\section{The Roles of Interlocutor in the Second Language Acquisition}

Interlocutor's social status. One striking feature of Elaine Tarone's paper is its citation of 3 sessions of a Bob, a Chinese boy's output under different circumstances, respectively with 3 different interlocutors: his teacher, primary-school peers and a researcher. Liu Guoqiang conducted 26-month longitudinal study of Bob, beginning when Bob was almost five years old and ending when he was almost seven. He observed Bob speaking English in Australia by means of analyzing his conversations with different interlocutors on recorded videotape [2].

In Bob's conversation with his teacher, Bob let the teacher take the conversational initiative, and limited his responses to utterances with relatively simple syntax. We may wonder that whether it is the real picture of Bob's English level. A further examination tells more.

Compared with the latter two sessions, it's not hard to find out that Bob's English proficiency in lexicon and syntax is not so disappointing. Especially in his interaction with the researcher, Bob demonstrated increased syntactic complexity, initiation, and variety of both structure and function. So Bob's performance in the conversation with the teacher was a very small part of his knowledge system. This pattern is consistent with Bob's cultural background, in which children are taught to show respect for their teachers, in part by "only speaking when spoken to", and to learn by listening to the teacher. Bob's deliberate self-restraint was to leave his teacher a good impression, so he didn't risk using utterances of which he was unsure.

Interlocutor's social status indeed has an effect on speaker's performance in second language output. Especially when the interlocutor enjoys a much higher social rank than the speaker, the speaker will subconsciously pay attention to his/her diction and sentence pattern so as to show due respect.

Speaker's self-restraint is not a phenomenon confined to Chinese culture. It is natural for people to adjust their interactive strategies to meet demands under different circumstances. These strategies may include intentional customs, special arrangements, gestures, as well as language. As learners, they may not be fully aware of the subtle differences between synonyms or similar sentence structures. This has further limited their choice in lexicon and syntax. Instead, they can only use those simple ones whose usages and implications are totally in their hands. To some extent, the higher interlocutor's social status is, the simpler words and sentences the speaker will use. In their eyes, those words and sentences are safe. This phenomenon exists not only in a conversation where both speaker and interlocutor are of the same language, but also is applicable when they are from different native languages.

Therefore, we can understand why Bob had totally different performances in the two groups of conversations. Interlocutor's social status, especially the relationship between the speaker and the interlocutor is taking effect. 
But why did Bob give such a different performance in his interaction with the researcher, who also enjoyed a higher social status than a five-year-old boy? Familiarity is the answer.

Interlocutor's familiarity with the speaker. A careful reading of the part concerned will offer a key word that describes the atmosphere of the conversation between Bob and the researcher: relaxed. It mentions that the researcher was a friend of the family, and an adult who knew how to play and was interested in interacting with Bob and drawing him out in a relaxed home environment. Bob's relationship with the researcher changed from a formal teacher-pupil relationship to a more relaxed "adult-friend" relationship, in which Bob felt free to disobey and even to insult the researcher.

Given Bob's young age, familiarity with the researcher made him forget the researcher's social status and feel free to say what he wanted. To a certain extent, Bob, under such circumstances, was the real Bob, because his performance in such interactions reflected his real proficiency in English.

Everyone has the experience that no matter in terms of content, fluency, or syntactic complexity, your talk with a foreign acquaintance is much more productive than that with a stranger. Because your closeness with the interlocutor in fact has created a relaxed environment in which you'll feel free to talk wider and deeper in scale and depth of the given topic, objectively giving a chance for you to employ more words and longer sentences to make your points clearly understood.

So, in a sense, familiarity just means that you know your diction and content of your speech will not set your interlocutor on fire, at least will not place yourself in a devastating and irrevocable consequence. You know that, because you have the faith. And your faith comes from your familiarity.

Familiarity with the interlocutor offers something more to the speaker, such as his/her language proficiency. A careful and detailed study of output of interlanguage from this perspective provides us with a good thinking for good communication with student, what's more important, for better teaching results.

Another question arises: why didn't Bob give the same level of performance in his interactions with the researcher and with his primary-school peers, with whom Bob had more or less the same familiarity.

Interlocutor's target language proficiency. According to Stephen Krashen's Input Hypothesis, a language acquirer who is at "level $i$ " must receive comprehensible input that is at "level $i+1$ ". We acquire, in other words, only when we understand language that contains structure that is "a little beyond" where we are now. In other words, the learner needs to be provided with input that is just a little beyond his/her present capacity; it is in the effort that s/he makes to comprehend the material that lies the source of her linguistic progress.

This hypothesis, to some extent, explains why Bob's performance was not as productive as that in his interaction with the researcher. In Session 43, we see:

BEN: You don't know because you don't know how to draw.

MARK: I don't know how to draw the whole world.

BOB: You don't know.

BEN: Do you know how to draw stars?

BOB: No he don't know.

These boys were all five years old or so, and they were engaged in a heated debate for which one of the two groups did a better job in painting. Though the rest were natives, they were not able to use advanced words and complex sentence patterns to argue. As a young foreign language learner in the initial stage of foreign language acquisition, Bob had to receive, digest, memorize and express 
the new words and sentences whenever he heard. In such an environment where his peers used only simple words and not-so complex sentences, Bob received and learned limited useful information and Bob would have definitely found that he had little resource to rely on when he wanted to make a sharp reply. That's reason why he repeated "You don't know" and "he don't know".

In classroom teaching, especially in listening-speaking class, conversation or even debate is commonly employed. We cannot afford to overlook that the low-level input from their interlocutors, usually their classmates, has locked them in the low-level output, such as using simple words and sentences, which most of the time are not suitable ones to fully express what is really on their mind. At such moments, teacher should play his/her due role by being full participants of the conversations and debates, though for some time as passive listeners only. But when they are over, the teachers should focus more on their linguistic performance, for instance, the improvement of collocation, syntactic complexity etc. During the whole process, teachers must be attentive, insight and be good at summarizing the advantages and disadvantages of each participant so as to ensure everyone will benefit from their participation.

Appropriateness of feedback. Good interactive feedback does not mean simple responses such as "Yes" or "No", nor direct, sharp even rude corrections. There are several shortcomings for this kind of feedback. Firstly, direct and sharp correction would interrupt speaker's thinking process, which even put an end to his/her speech, thus depriving the opportunity for further observation of speaker's performance. Secondly, this kind of feedback would do harm to students' self-esteem. The willingness to speak, in particular, to dare speak in public matters. So teachers should try best to mobilize, guide, protect and encourage their precious willingness to show themselves and join them in celebrating their every step forward in learning, which will make them feel they are watched with care and they have the impetus to learn more and show more. Instead, feedbacks should be introductory, incentive, and thought-provoking.

\section{Conclusion}

The above-mentioned four aspects are just a small fraction of the total roles of interlocutor in second language acquisition, which in the final analysis, deserves our further attention and research. Especially, in foreign language teaching, a better knowledge in this regard will teachers understand the law of second language acquisition and provide students with better input and methods for their better grasp of the target language.

\section{References}

[1] Merrill Swain, Three Functions of Output in Second Language Learning, in G. Cook, B. Seidlhofer (Eds), Principle and Practice in Applied Linguistics: Studies in Honour of H.G. Widdowson. Oxford University Press, Oxford, 1995.

[2] Elaine Tarone, Liu Guoqiang, Situational Context, Variation, and Second Language Acquisition Theory, in G. Cook, B. Seidlhofer (Eds), Principle and Practice in Applied Linguistics: Studies in Honour of H.G. Widdowson. Oxford University Press, Oxford, 1995. 